\title{
Study Start
}

National Cancer Institute

\section{Source}

National Cancer Institute. Study Start. NCI Thesaurus. Code C142714.

The official beginning of a clinical study, as specified in the clinical study report. 